\begin{tabular}{cc} 
Journal of Environmental \\
Analysis and Progress \\
ISSN: $2525-815 \mathrm{X}$ & Journal homepage: $\underline{\text { www.jeap.ufrpe.br/ }}$ \\
\hline
\end{tabular}

\title{
Caracterização morfométrica e microbiota endógena de populações do marisco Anomalocardia flexuosa Linnaeus, 1767 (Bivalvia: Veneridae)
}

\section{Morphometric characterization and endogenous microbiota of shellfish Anomalocardia flexuosa Linnaeus, 1767 (Bivalvia: Veneridae)}

\author{
Carlos Henrique de Vasconcelos Nascimento ${ }^{a}$, Ivo Raposo Gonçalves Cidreira Neto ${ }^{\text {a }}$, Rafael \\ Pereira da Silva ${ }^{a}$, José Eriberto de Assis ${ }^{a}$, Norma Buarque Gusmão ${ }^{a}$, Gilberto Gonçalves Rodrigues ${ }^{a}$ \\ a Universidade Federal de Pernambuco-UFPE, Av. Prof. Moraes Rego, n 1235, Cidade Universitária, Recife, \\ Pernambuco. CEP: 50670-971. E-mail: carlos.vasconcelos46@gmail.com; ivo.raposo@hotmail.com; \\ rafaelpsilva@gmail.com; eri.assis@gmail.com; normagusmao@gmail.com; gilberto.rodrigues@ufpe.br.
}

\begin{tabular}{l}
\hline A R T I C L E I N F O \\
\hline Recebido 27 Abr 2018 \\
Aceito 05 Jul 2018 \\
Publicado 19 Jul 2018
\end{tabular}

\begin{abstract}
A B S T R A C T
The harvesting of Anomalocardia flexuosa L. shellfish is essential for traditional communities, which live in coastal regions and depend on this activity. The study aimed to investigate the endogenous microbiota of $A$. flexuosa associated with shell morphometry. Samples were collected in the estuary of the Paraiba do Norte River, in September-October 2017, in four different levels of water pollution. The shellfish were collected manually, and the river water was collected with polyethylene bottle. The morphometry of the shellfish was made with pachymeter, and the inoculation for the growth of the microorganisms was done using the means Sabouraud Agar (SAB) and Malte for fungi and Agar Tryptic soy (TSA) and Mueller Hinton (MH) for bacteria. Shell sizes of $14.14 \mathrm{~mm}$ to $21.56 \mathrm{~mm}$ and 33 morphotypes of the microbiota were found, being 14 of bacteria and 19 of fungi. The individuals of the croa Cidade, because they are closer to the urban zone, receive a higher pollution load, reflecting in the average size of the shells of the $A$. flexuosa populations. The most conserved and distant of the urban center (Portinho, Marisco and Lombo da Vara) had a higher richness of endogenous bacteria, whereas the fungi did not present significant statistical difference, associated with the average bigger size of the shell. Mitigative measures are necessary for the best performance of the shellfish activity, taking as a presupposition the minimization of water pollution from urban centers and the adequate handling of shellfish.
\end{abstract}

Keywords: Artisanal fishing, shellfish, croas, aquatic fungi, bacteria. 
ao tamanho médio maior da concha. Medidas mitigatórias são necessárias para o melhor rendimento da atividade de catação de marisco, tendo como pressuposto a minimização da poluição hídrica, advinda dos centros urbanos e o manejo adequado da mariscagem.

Palavras-Chave: Pesca artesanal, mariscos, croas, fungos aquáticos, bactérias.

\section{Introdução}

O marisco Anomalocardia flexuosa (Linnaeus, 1767) pertence à família Veneridae, a qual reúne doze subfamílias, cinquenta gêneros e cerca de cinquenta espécies. Eles apresentam grande capacidade de adaptação em diferentes meios, como praias arenosas, areno-lodosas, manguezais e fundos arenosos em ambientes coralíneos (Rodrigues, Borges-Azevedo \& HenrySilva, 2010). No Brasil, a espécie é conhecida como "berbigão", "vongole", "mija-mija", "sarnambi", "sarnambi pequeno", "samanguaiá", "papa-fumo", "sarro-de-pito", "marisco-pedra" e "maçunim" (Luz \& Boehs, 2011). A espécie A. flexuosa é caracterizada por apresentar concha com formato trigonal, inflada, sólida, com uma forte carena radial delimitando a região dorsal posterior de sua concha. Além disso, apresenta uma coloração externa com tons de creme com desenhos e cores variadas, é dióica, com reprodução externa sexuada com ciclo de vida complexo com um estágio larval relativamente curto de 11 a 30 dias. A sua distribuição vai desde as Índias Ocidentais até o Uruguai e ocorre em toda costa brasileira (Rodrigues, Borges-Azevedo \& Henry-Silva, 2010). Em seu processo fisiológico de filtração, os moluscos bivalves chegam a filtrar de 19 a 50 litros de água por hora e com isso acumulam na massa visceral, lúmen do intestino e hepatopâncreas todos os agentes biológicos e abióticos que se encontram na água onde vivem. Esses micro-organismos, em sua maioria fungos e bactérias, presentes na água e na microbiota do marisco A. flexuosa, podem ser utilizados como indicadores de contaminação ambiental ou estarem presentes na microbiota natural do organismo sem causar nenhum dano (Pinto, 2012). Historicamente, no Nordeste do Brasil, a mariscagem é realizada principalmente por mulheres, durante o ano todo, e não existe um ordenamento na extração, evitando a superexploração, apesar de ser uma espécie abundante e um recurso de baixa estocagem (Rocha, 2013). Dentre essas atividades de pesca artesanal, se destacam a catação de guaiamum, caranguejo do mangue ou uçá, aratu e camarão (crustáceos) e marisco-pedra, marisco-rei, taioba, catapuz, sururu, unha de veio e ostras (moluscos). A execução da catação do marisco-pedra é feita no período de maré baixa em locais denominados de croas, que são bancos areno-lodosos de sedimento, que ocorrem em planícies de maré (Baracho, 2016).

Cidreira-Neto (2018) aponta que, quando se usa apetrechos como o puçá, o gadanho e o jereré, para aumentar a produtividade, aliada ao uso de embarcações com motores a diesel, estes podem influenciar na disponibilidade de populações marisco com tamanho adequado a mariscagem. $\mathrm{O}$ presente estudo teve como objetivo investigar a microbiota endógena de $A$. flexuosa associada à morfometria da concha do marisco-pedra ao longo de um gradiente de do estuário do rio Paraíba do Norte.

\section{Material e Métodos}

O estuário do Rio Paraíba do Norte situase na porção mediana do Estado da Paraíba e possui uma bacia hidrográfica com extensão de, aproximadamente, $380 \mathrm{~km}$, passando por 37 municípios. O estuário subdivide-se em Alto, Médio e Baixo Paraíba (Nishida, Nordi \& Alves, 2004).

A vegetação que ocorre na área é caracterizada por florestas de Mata Atlântica, manguezais e restinga. Nas áreas de manguezais, ocorrem as espécies Rizophora mangle L. (mangue vermelho), Avicennia schaueriana Stapf \& Leechm. ex Moldenke (mangue siriuba), Conocarpus erectus L. (mangue de botão), Laguncularia racemosa (L.) C.F. Gaertn. (mangue branco), Dalbergia ecastophillum L. Taub. e Annona glabra L., que são espécies associadas comumente encontradas na região (Guedes, 2002; Nishida, Nordi \& Alves, 2004).

Segundo a classificação de Köppen, o clima do estuário é do tipo As' (Tropical Quente Úmido), com um período chuvoso, de março a agosto, e outro seco, de estiagem, de setembro a dezembro (Cavalcanti, 2003).

O município de Bayeux-PB localiza-se na planície flúvio marinha, é banhado pelo rio Sanhauá, um dos afluentes do estuário do Rio Paraíba. Segundo o IBGE e o último censo (2010), a população é de 99.716 habitantes e a extensão da área de unidade territorial é de 27.536 $\mathrm{km}^{2}$.

A coleta dos mariscos e água do estuário ocorreu no mês de setembro e outubro de 2017, sendo realizada, de forma manual, em quatro croas ao longo do estuário: Cidade ( $7^{\circ} 06^{\prime} 11,8^{\prime}$ 'S; $34^{\circ} 53^{\prime} 46,9^{\prime}$ 'W), $\quad$ Portinho $\quad\left(7^{\circ} 0,5^{\prime} 28,9^{\prime}\right.$ 'S; 
$34^{\circ} 53^{\prime} 45,1^{\prime}$ 'W), Croa do Marisco ( $7^{\circ} 0,5^{\prime} 0,3.1^{\prime}$ 'S; $34^{\circ} 53^{\prime} 0,6.0^{\prime \prime}$ 'W) e Lombo da Vara $\left(7^{\circ} 4^{\prime} 43,4^{\prime \prime}\right.$ 'S; $34^{\circ} 52^{\prime} 49,9^{\prime}$ ' $\mathrm{W}$ ), sendo realizadas a partir do Porto Oficina (base), local mais à montante da foz, onde deixa de existir a mariscagem (Figura 1).

A escolha das croas foi feita com o auxílio das marisqueiras, a partir do conhecimento empírico que elas possuem, quando foram indicadas croas onde ocorre a mariscagem e que apresentaram diferentes níveis de influência antrópica no ambiente.
A morfometria da concha do marisco foi realizada com auxílio de paquímetro digital, considerando as medidas de comprimento (dimensão entre o umbo e a borda da cocha), a largura (máxima dimensão entre a região anteroposterior) e altura (máxima dimensão entre as duas valvas) (Figura 2).

A análise dos dados morfométricos foi feita através do programa BioEstat 5.0, aplicando correlações entre todas as medidas para verificar se existe relação funcional entre essas variáveis.
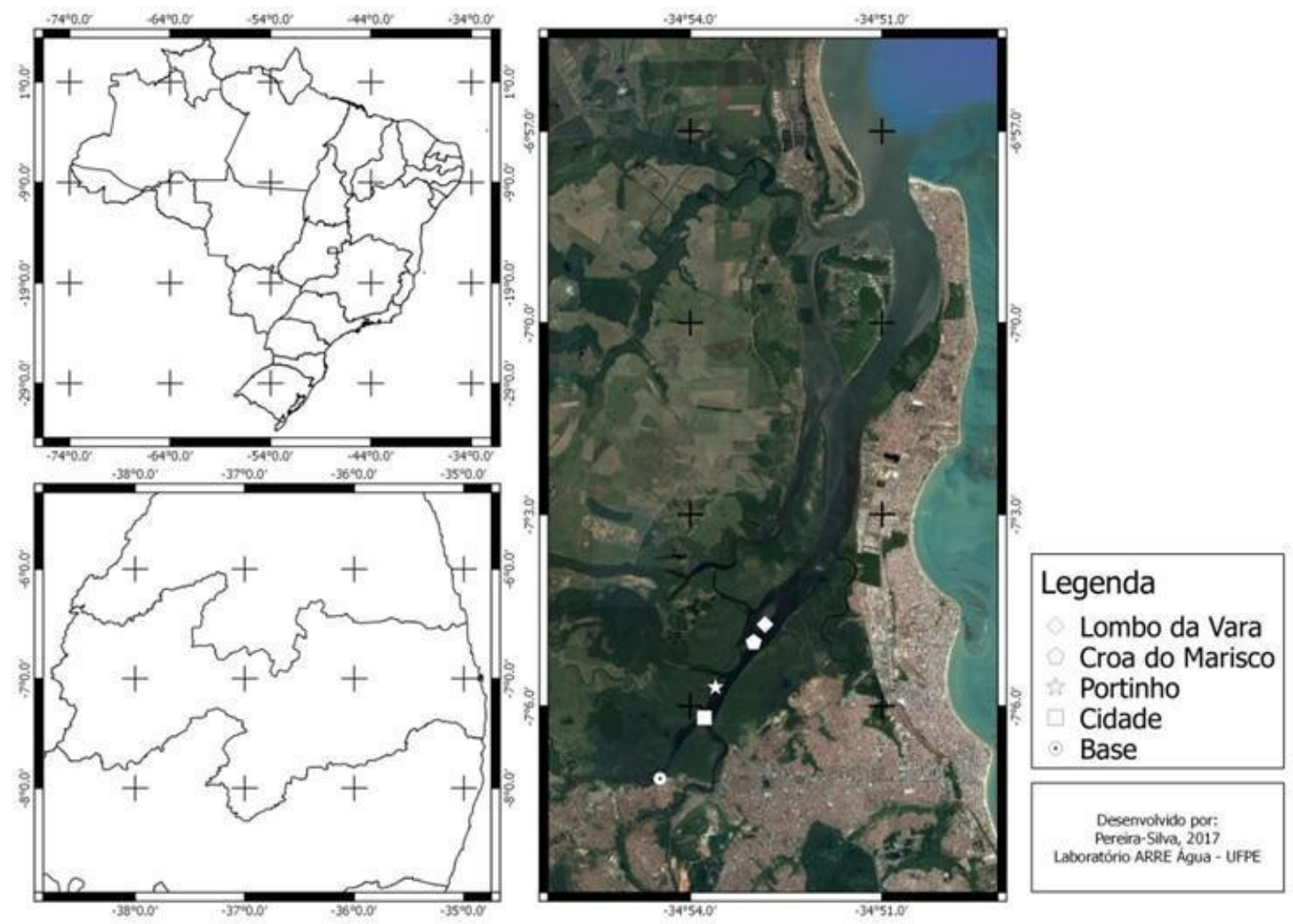

Figura 1. Mapa da localização do município de Bayeux, na Paraíba, evidenciando a localização das croas selecionadas para a coleta dos mariscos e da água do estuário. Fonte: Autores (2017).
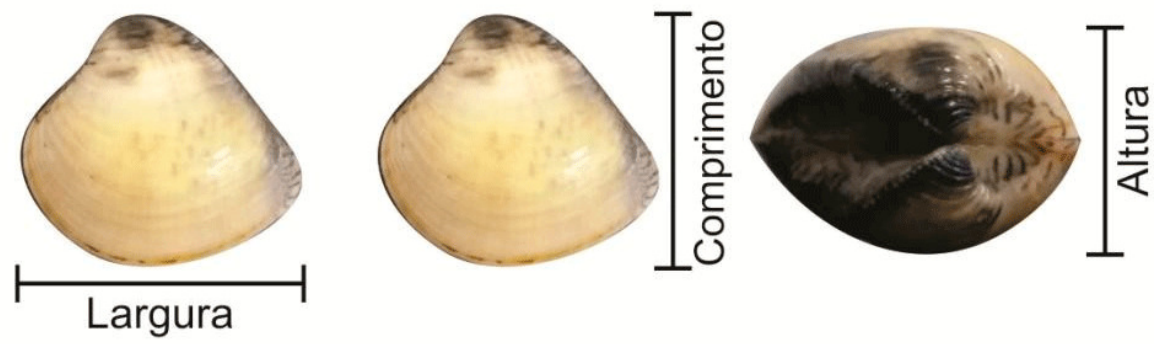

Figura 2. Morfometria da concha de Anomalocardia flexuosa L. (largura $\mathrm{Lc}=2 \mathrm{~cm}$, comprimento $\mathrm{Cc}=2$ $\mathrm{cm}$, altura $\mathrm{Ac}=1,8 \mathrm{~cm})$. Fonte: Autores (2017).

Em laboratório, após o período de acondicionamento no freezer, foram realizadas lavagens para desinfecção das amostras em quatro séries, por um minuto em cada série (Figura 3A). A primeira, com água sanitária (4\%), e as três posteriores com água destilada esterilizada. A última água de lavagem foi inoculada com auxílio de um "swab" para o tratamento controle, a fim de eliminar todos os microrganismos presentes na parte externa da concha. Em seguida, foi feita a 
abertura das conchas com auxílio de bisturi e pinça para o corte das partes mole, e cortados em frações de aproximadamente $1 \mathrm{~cm}^{2}$ (Figura $3 \mathrm{~B}$ e 3C) e transferidos para os meios Agar Tryptic soy (TSA), Mueller Hinton (MH) suplementados com fluconazol para as bactérias. Para os fungos foram utilizados os meios Ágar Sabouraud (SAB) e ágar malte (MALTE) suplementados com cloranfenicol + tetraciclina. Todas as placas de Petri foram acondicionadas em estufa a $30^{\circ} \mathrm{C}$, por $24 \mathrm{~h}$, para as bactérias e, até quatro dias, para os fungos. Todo o ensaio foi realizado em triplicata.

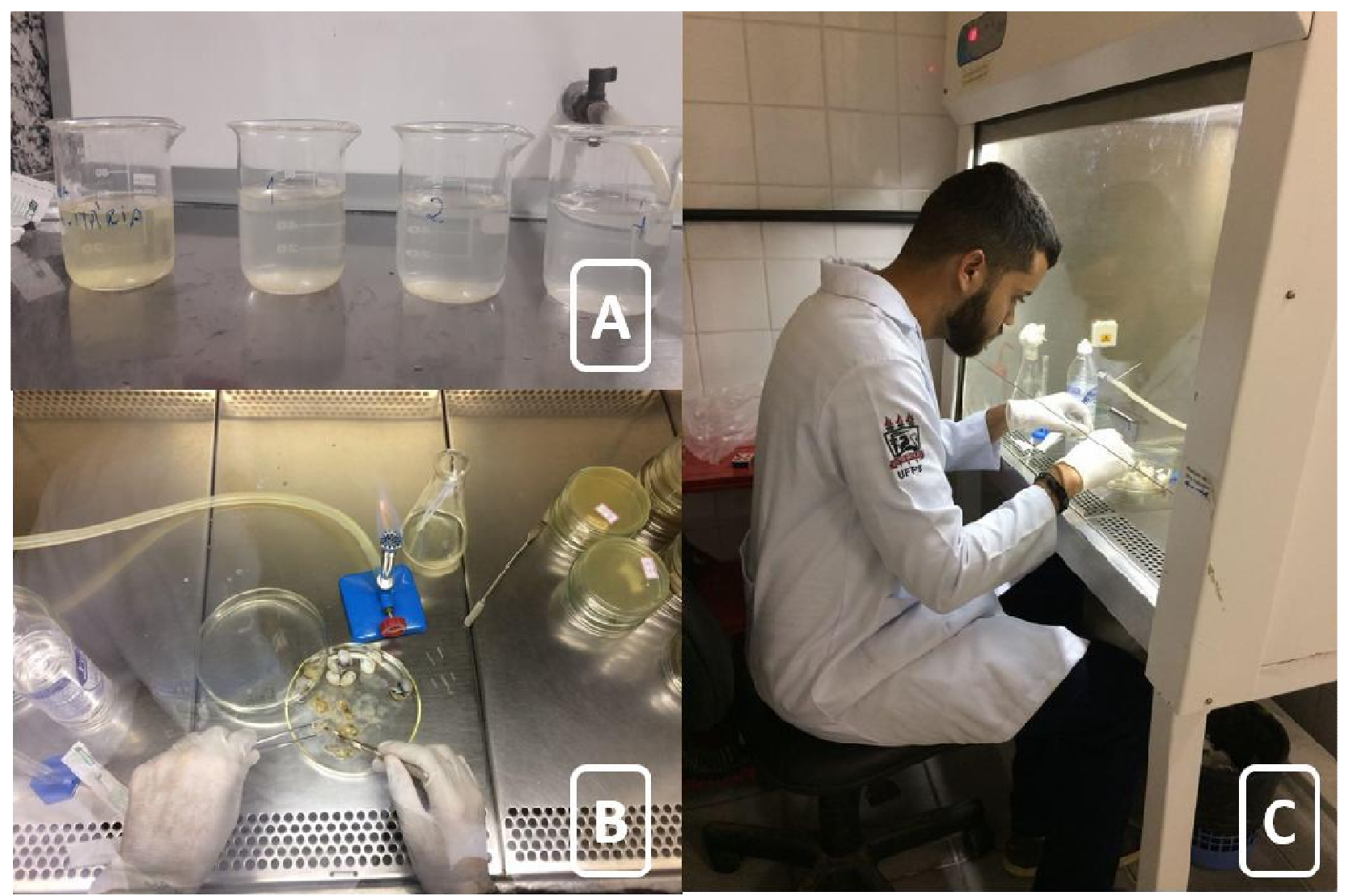

Figura 3. Procedimentos para a inoculação dos mariscos em placas de Petri. A. Lavagem dos mariscos com água sanitária e água destilada esterilizada; B. Corte do corpo mole dos mariscos; C. Secção do corpo mole realizado em câmara de fluxo laminar. Fonte: Autores (2017).

\section{Resultados}

Foram analisadas amostras com 30 mariscos em cada croa, totalizando 120 individuos.

Lombo da Vara (LV), a croa mais distante do Porto Oficina, apresentou as maiores médias em todas as medidas, comprimento $(21,56 \pm 0,52$ $\mathrm{mm})$, largura $(25,58 \pm 0,15 \mathrm{~mm})$ e altura $(15,24 \pm$ $0,49 \mathrm{~mm}$ ). Em contrapartida, Cidade (C), a croa mais próxima da base, apresentou as menores médias de comprimento $(14,14 \pm 0,03 \mathrm{~mm})$, largura $(18,63 \pm 0,17 \mathrm{~mm})$ e altura $(8,34 \pm 0,05$ $\mathrm{mm})$. As croas Portinho (P) e do Marisco (M) apresentaram medidas próximas, não havendo alta variação, como ocorreu entre Cidade e Lombo da Vara. Portinho apresentou comprimento (19,97 \pm $0,13 \mathrm{~mm})$, largura $(24,97 \pm 0,71 \mathrm{~mm})$ e altura $(15,12 \pm 0,10 \mathrm{~mm})$ e Croa do Marisco apresentou comprimento $(20,27 \pm 1,81 \mathrm{~mm})$, largura $(24,09 \pm$ $0,94 \mathrm{~mm})$ e altura $(14,24 \pm 1,52 \mathrm{~mm})$. As correlações entre as medidas morfométricas (Tabela 1) e os valores encontrados foram significativos, cujo menor valor foi de $14 \%$ (largura versus altura) para Cidade, sendo considerada uma correlação fraca e o maior valor de 98,7\% (largura versus altura) para Portinho, considerada uma correlação forte. Em relação aos gráficos de dispersão (Figuras 4 e 5) e o valor das regressões, dentre as croas analisadas, a maioria teve relações entre as medidas com crescimento exponencial e o valor do $\mathrm{R}$ quadrado próximo de 1 , ou seja, houve uma maior validade da regressão nas croas Portinho, Marisco e Lombo da Vara. Apenas a croa Cidade teve um crescimento linear e o valor do $\mathrm{R}$ mais próximo de 0 . 
Tabela 1. Correlações entre as medidas morfométricas: comprimento (Cc), largura (Lc) e altura (Ac) em cada ponto de coleta. $\mathrm{C}=$ croa Cidade; $\mathrm{P}=$ croa Portinho; $\mathrm{M}=$ Croa do Marisco; $\mathrm{LV}=$ croa Lombo da Vara. Fonte: Autores (2017).

\begin{tabular}{l|c|c|c|c}
\hline Morfometria/Croas & C & P & M & LV \\
\hline $\mathrm{Cc} \times \mathrm{Lc}$ & 0,657 & 0,984 & 0,967 & 0,959 \\
\hline $\mathrm{Cc} \times \mathrm{Ac}$ & 0,532 & 0,979 & 0,951 & 0,898 \\
\hline $\mathrm{Lc} \times \mathrm{Ac}$ & 0,143 & 0,987 & 0,954 & 0,9387 \\
\hline
\end{tabular}

Em relação ao tratamento controle, não houve crescimento de micro-organismos. No total, foram encontradas 33 morfotipos da microbiota endógena associada a A. flexuosa, com 14 morfotipos de bactérias (Figura 5) e (Tabela 2), oito ocorrendo na croa Cidade; oito em Portinho; oito na Croa do Marisco e 11 no Lombo da Vara. Apenas B11 esteve presente no tratamento água do estuário, em todas as croas. B12, exclusivo da Lombo da Vara, é, possivelmente, uma espécie sensível às variações ambientais.

Em relação aos fungos foram encontrados 19 morfotipos aquáticos (Figura 6) e (Tabela 3), cinco ocorrendo nas croas Cidade, Portinho, Lombo da Vara e seis ocorrendo na croa do Marisco. No tratamento Água ocorreram seis morfotipos de bactérias e 14 de fungos.

A ocorrência dos morfotipos de fungos F4, F7, F8 e F10 (Tabela 3) é compartilhada com o tratamento Água do Estuário e a microbiota endógena (corpo mole) do marisco-pedra. Os demais morfotipos de fungos (F11 a F19), são exclusivos do corpo mole (endógenos) e possivelmente vivem em associação com os mariscos. Os morfotipos F18 e F19 são exclusivos da croa Cidade.
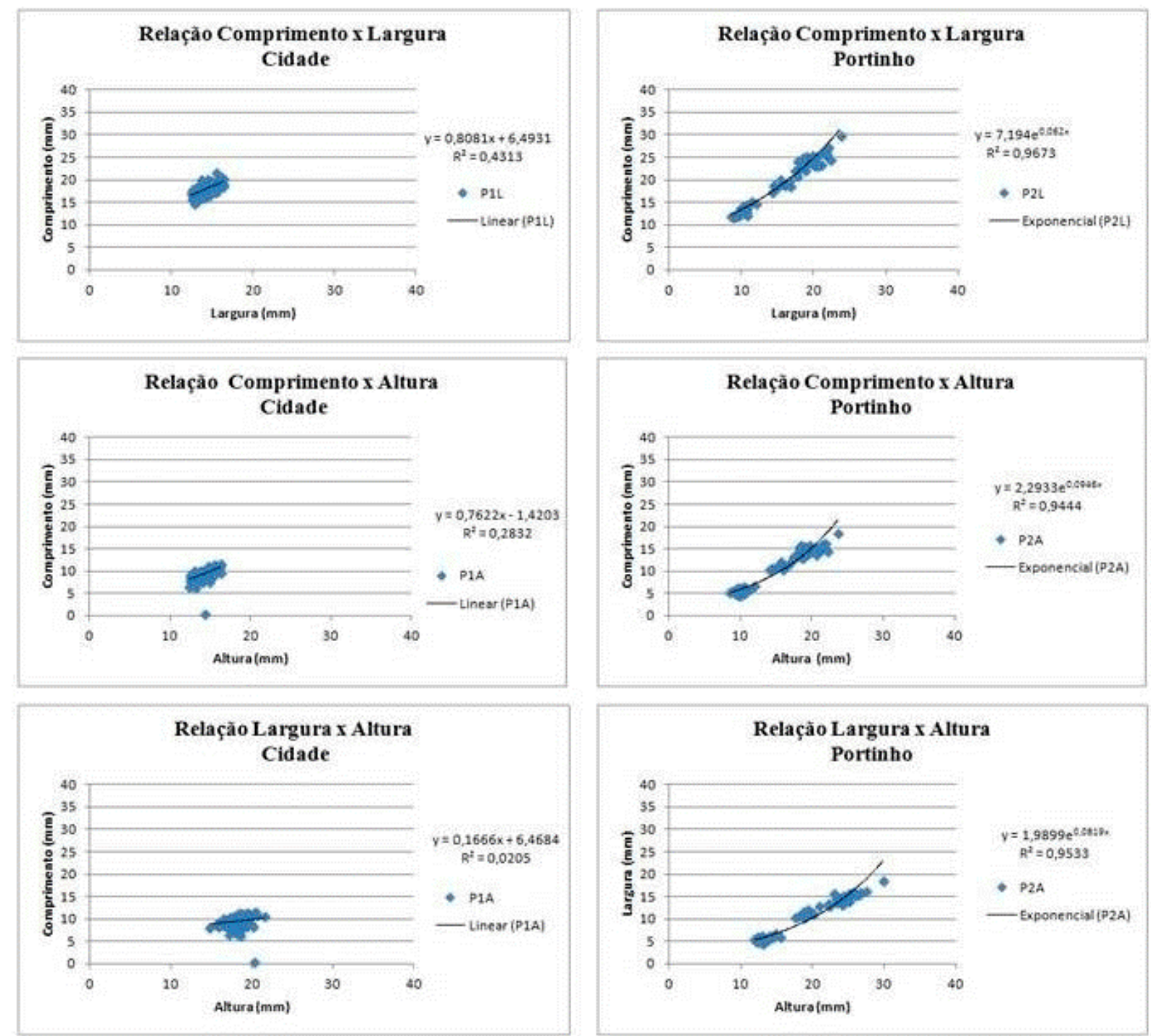

Figura 4. Gráficos de dispersão entre as medidas morfométricas de Anomalocardia flexuosa L. nas croas Cidade e Portinho. Fonte: Autores (2017). 

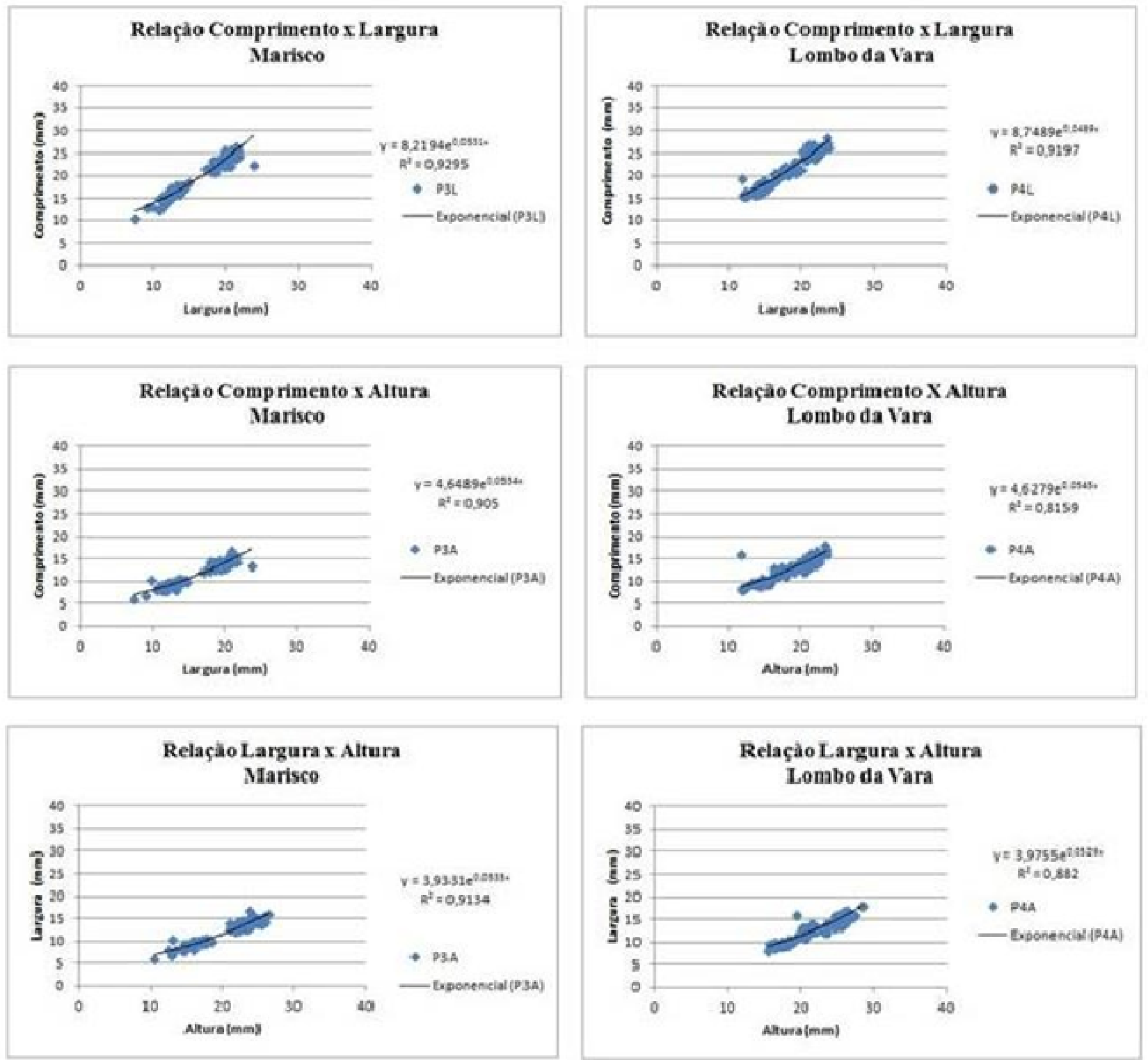

Figura 5. Gráficos de dispersão entre as medidas morfométricas de Anomalocardia flexuosa L. nas Croas do Marisco e Lombo da Vara. Fonte: Autores (2017). 


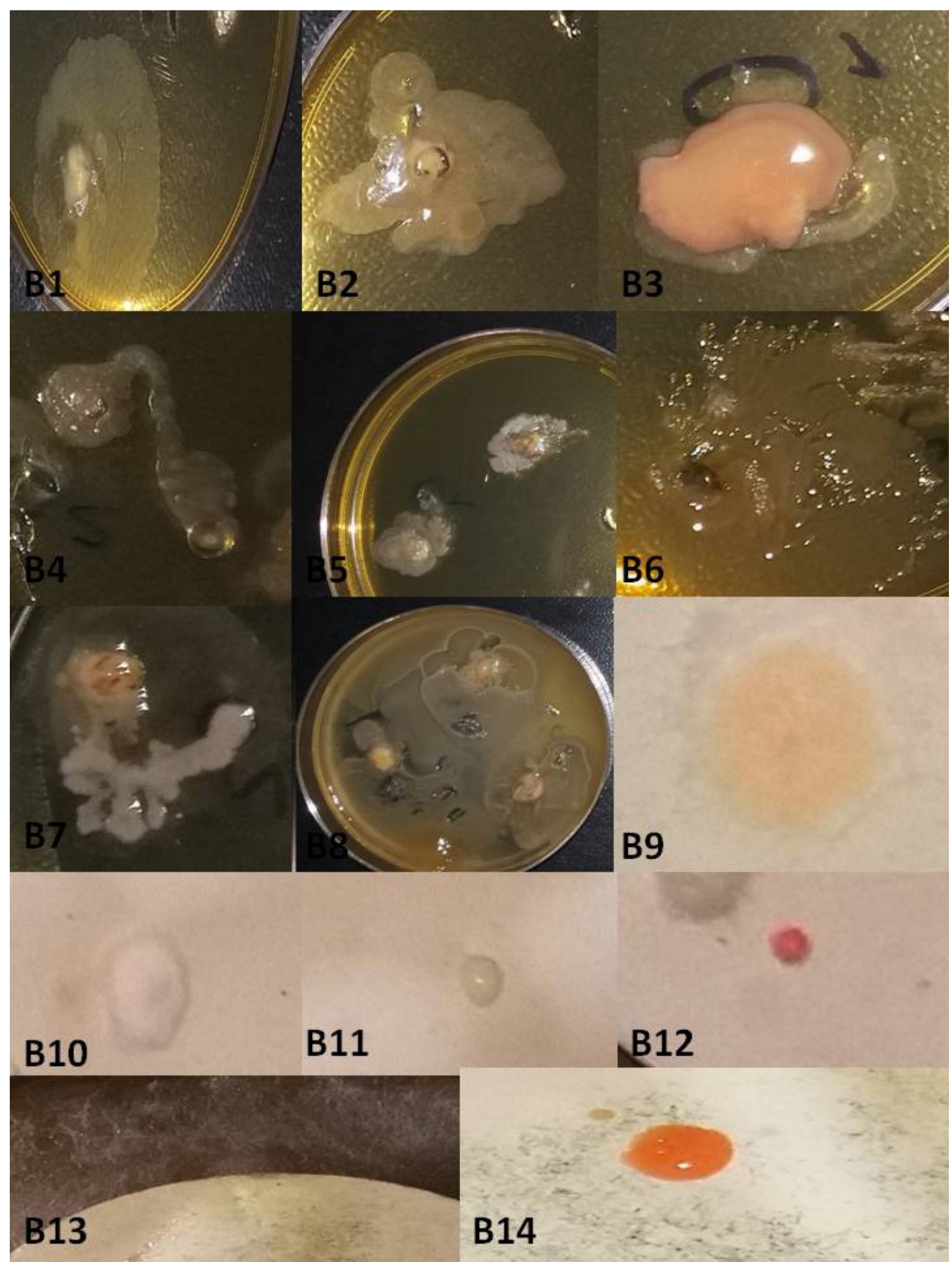

Figura 6. Morfotipos (MF) de bactérias encontrados no interior do marisco-pedra Anomalocardia flexuosa L. e na água ao longo do trecho inferior do Rio Paraíba do Norte, Paraíba. Fonte: Autores (2017).

Tabela 2. Morfotipos (MF) de bactérias presentes no estuário do Rio Paraíba do Norte-PB em três tratamentos (controle, corpo mole e água) de análise nas quatro croas: $\mathrm{C}=$ croa Cidade; $\mathrm{P}=$ croa Portinho; $\mathrm{M}$ = croa do Marisco, LV = croa Lombo da Vara. MF: Morfotipo; Ausência (-); Presença (X). Fonte: Autores (2017).

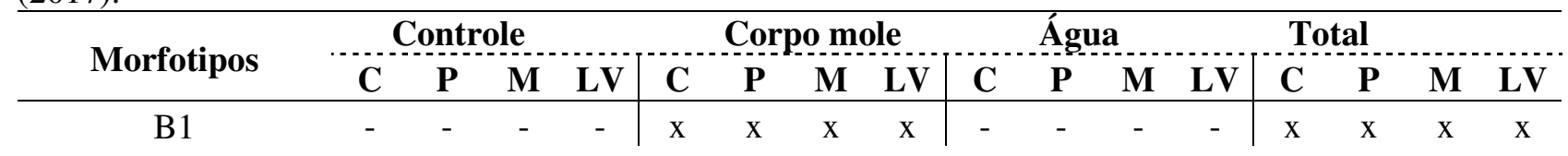


Journal of Environmental Analysis and Progress V. 03 N. 03 (2018) 275-286

\begin{tabular}{llllll|lllll|llll|llll} 
& B2 & - & - & - & - & $\mathrm{x}$ & $\mathrm{x}$ & $\mathrm{x}$ & $\mathrm{x}$ & - & - & - & - & $\mathrm{x}$ & $\mathrm{x}$ & $\mathrm{x}$ & $\mathrm{x}$ \\
& B3 & - & - & - & - & - & - & - & $\mathrm{x}$ & - & - & - & - & - & - & - & $\mathrm{x}$ \\
& B4 & - & - & - & - & - & - & $\mathrm{x}$ & - & - & - & - & - & - & - & $\mathrm{x}$ & - \\
& B5 & - & - & - & - & $\mathrm{x}$ & $\mathrm{x}$ & $\mathrm{x}$ & $\mathrm{x}$ & - & - & - & - & $\mathrm{x}$ & $\mathrm{x}$ & $\mathrm{x}$ & $\mathrm{x}$ \\
& B6 & - & - & - & - & - & $\mathrm{x}$ & - & $\mathrm{x}$ & - & - & - & - & - & $\mathrm{x}$ & - & $\mathrm{x}$ \\
& B7 & - & - & - & - & - & - & - & $\mathrm{x}$ & - & - & - & - & - & - & - & $\mathrm{x}$ \\
& B8 & - & - & - & - & $\mathrm{x}$ & $\mathrm{x}$ & $\mathrm{x}$ & $\mathrm{x}$ & - & - & - & - & $\mathrm{x}$ & $\mathrm{x}$ & $\mathrm{x}$ & $\mathrm{x}$ \\
& B9 & - & - & - & - & - & - & - & - & - & $\mathrm{x}$ & $\mathrm{x}$ & $\mathrm{x}$ & - & $\mathrm{x}$ & $\mathrm{x}$ & $\mathrm{x}$ \\
& B10 & - & - & - & - & - & - & - & - & $\mathrm{x}$ & - & - & $\mathrm{x}$ & $\mathrm{x}$ & - & - & $\mathrm{x}$ \\
& B11 & - & - & - & - & - & - & - & - & $\mathrm{x}$ & $\mathrm{x}$ & $\mathrm{x}$ & $\mathrm{x}$ & $\mathrm{x}$ & $\mathrm{x}$ & $\mathrm{x}$ & $\mathrm{x}$ \\
B13 & B12 & - & - & - & - & - & - & - & - & - & - & - & $\mathrm{x}$ & - & - & - & $\mathrm{x}$ \\
B14 & & - & - & - & - & - & - & - & - & $\mathrm{x}$ & $\mathrm{x}$ & $\mathrm{x}$ & - & $\mathrm{x}$ & $\mathrm{x}$ & $\mathrm{x}$ & - \\
Total & & - & - & - & - & - & - & - & - & $\mathrm{x}$ & - & - & - & $\mathrm{x}$ & - & - & - \\
\hline
\end{tabular}

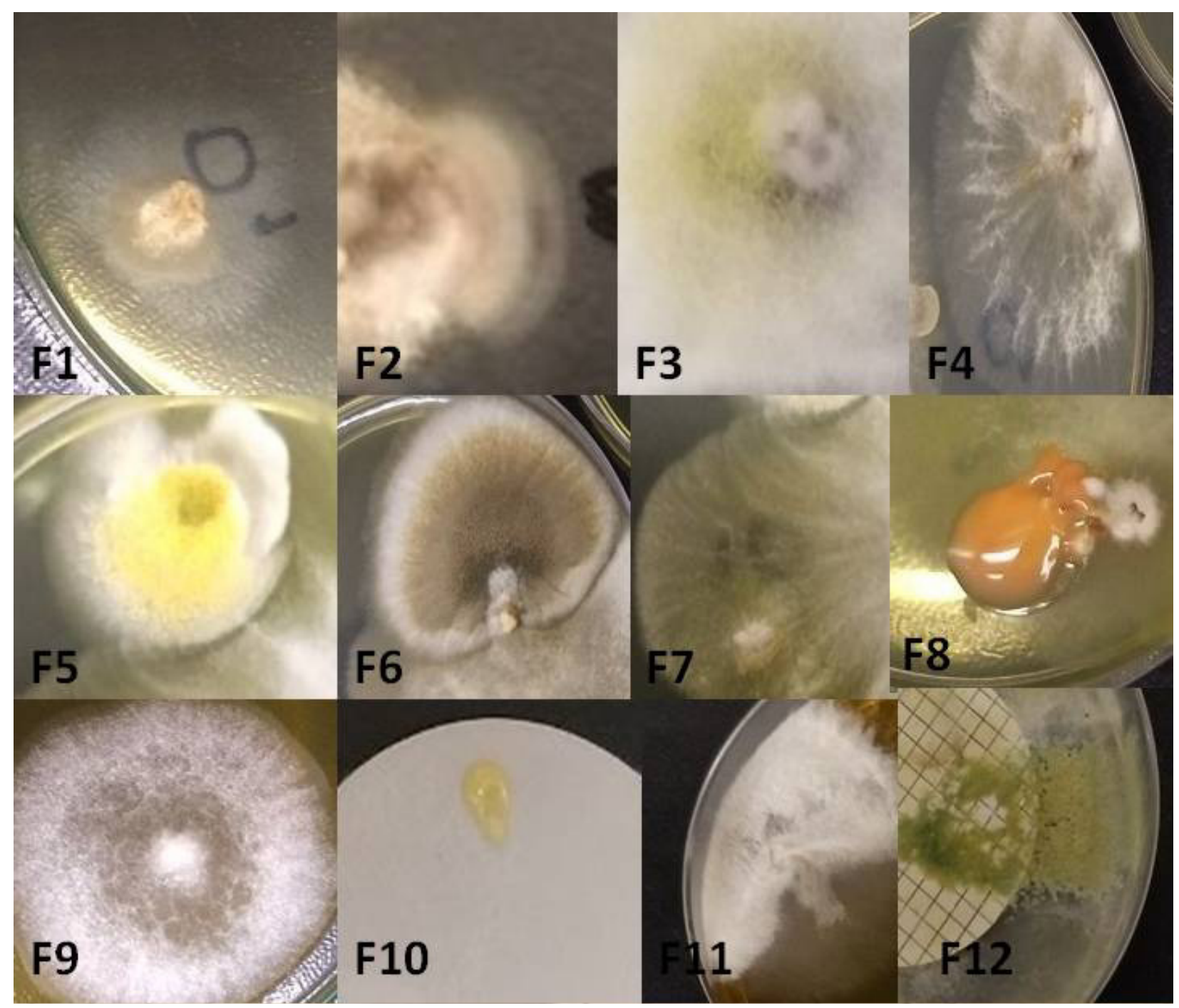




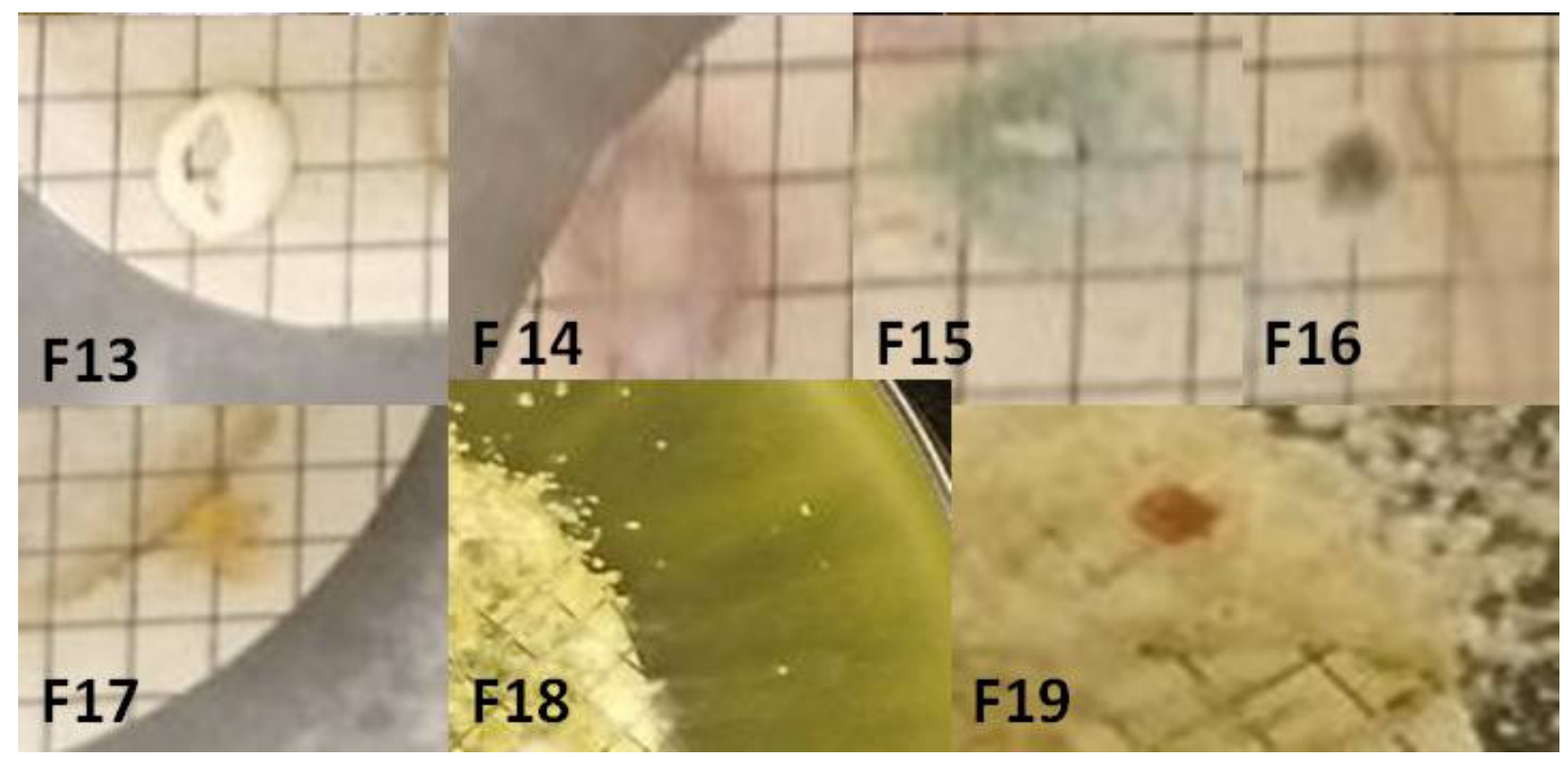

Figura 7. Morfotipos (MF) de fungos encontrados no interior do marisco-pedra Anomalocardia flexuosa L. e na água ao longo do trecho inferior do Rio Paraíba do Norte, Paraíba. Fonte: Autores (2017).

Tabela 3. Morfotipos de fungos presentes no estuário do Rio Paraíba do Norte em três tratamentos (controle, corpo mole e água) de análise nas quatro croas (C: croa da Cidade; P: croa do Portinho; M: croa do Marisco e LV: croa Lombo da Vara). Fonte: Autores (2017).

\begin{tabular}{|c|c|c|c|c|c|c|c|c|c|c|c|c|c|c|c|c|}
\hline \multirow{2}{*}{$\begin{array}{c}\text { Tratamentos } \\
\text { Morfotipos }\end{array}$} & \multicolumn{4}{|c|}{ Controle } & \multicolumn{4}{|c|}{ Corpo mole } & \multicolumn{4}{|c|}{ Água } & \multicolumn{4}{|c|}{ Total } \\
\hline & C & $\mathbf{P}$ & $\mathbf{M}$ & $\mathbf{L V}$ & C & $\mathbf{P}$ & $\mathbf{M}$ & $\mathbf{L V}$ & C & $\mathbf{P}$ & $\mathbf{M}$ & LV & C & $\mathbf{P}$ & M & LV \\
\hline MF1 & - & - & - & - & $\mathrm{x}$ & - & $\mathrm{x}$ & $\mathrm{x}$ & - & - & - & - & $\mathrm{x}$ & - & $\mathrm{x}$ & $\mathrm{x}$ \\
\hline MF2 & - & - & - & - & - & $\mathrm{x}$ & $\mathrm{x}$ & $\mathrm{x}$ & - & - & - & - & - & $\mathrm{x}$ & $\mathrm{x}$ & $\mathrm{x}$ \\
\hline MF3 & - & - & - & - & - & - & $\mathrm{x}$ & $\mathrm{x}$ & - & - & - & - & - & - & $\mathrm{x}$ & $\mathrm{x}$ \\
\hline MF4 & - & - & - & - & $\mathrm{x}$ & $\mathrm{x}$ & - & $\mathrm{x}$ & - & - & - & $\mathrm{x}$ & $\mathrm{x}$ & $\mathrm{x}$ & - & $\mathrm{x}$ \\
\hline MF5 & - & - & - & - & - & $\mathrm{x}$ & - & - & - & - & - & - & - & $\mathrm{x}$ & - & - \\
\hline MF6 & - & - & - & - & - & $\mathrm{x}$ & - & - & - & - & - & - & - & $\mathrm{x}$ & - & - \\
\hline MF7 & - & - & - & - & $\mathrm{x}$ & $\mathrm{x}$ & $\mathrm{x}$ & - & - & $\mathrm{x}$ & $\mathrm{x}$ & - & $\mathrm{x}$ & $\mathrm{x}$ & $\mathrm{x}$ & - \\
\hline MF8 & - & - & - & - & $\mathrm{x}$ & - & - & - & - & - & - & $\mathrm{x}$ & $\mathrm{x}$ & - & - & $\mathrm{x}$ \\
\hline MF9 & - & - & - & - & $\mathrm{x}$ & - & $\mathrm{x}$ & $x$ & $\mathrm{x}$ & $\mathrm{x}$ & - & - & $\mathrm{x}$ & $x$ & $x$ & $\mathrm{x}$ \\
\hline MF10 & - & - & - & - & - & - & $\mathrm{x}$ & - & - & - & $\mathrm{x}$ & - & - & - & $\mathrm{x}$ & - \\
\hline MF11 & - & - & - & - & - & - & - & - & - & - & - & $\mathrm{x}$ & - & - & - & $\mathrm{x}$ \\
\hline MF12 & - & - & - & - & - & - & - & - & - & - & $\mathrm{x}$ & - & - & - & $\mathrm{x}$ & - \\
\hline MF13 & - & - & - & - & - & - & - & - & - & - & $\mathrm{x}$ & - & - & - & $\mathrm{x}$ & - \\
\hline MF14 & - & - & - & - & - & - & - & - & - & - & $\mathrm{x}$ & - & - & - & $\mathrm{x}$ & - \\
\hline MF15 & - & - & - & - & - & - & - & - & - & - & $\mathrm{x}$ & - & - & - & $\mathrm{x}$ & - \\
\hline MF16 & - & - & - & - & - & - & - & - & - & - & $\mathrm{x}$ & - & - & - & $\mathrm{x}$ & - \\
\hline MF17 & - & - & - & - & - & - & - & - & - & - & $\mathrm{x}$ & - & - & - & $\mathrm{x}$ & - \\
\hline MF18 & - & - & - & - & - & - & - & - & $\mathrm{x}$ & - & - & - & $\mathrm{x}$ & - & - & - \\
\hline MF19 & - & - & - & - & - & - & - & - & $\mathrm{x}$ & - & - & - & $\mathrm{x}$ & - & - & - \\
\hline Total & - & - & - & - & 5 & 5 & 6 & 5 & 3 & 2 & 8 & 3 & 7 & 6 & 12 & 7 \\
\hline
\end{tabular}

\section{Discussão}

Neste estudo, a análise morfométrica dos mariscos foi realizada ao longo de um gradiente de poluição, a partir de efluentes de esgotos que são transportados pelo rio Sanhauá, tomando como partida o ponto do Porto Oficina (base), onde não ocorre mais a presença do marisco-pedra A. flexuosa. À jusante do Porto Oficina, no Rio Paraíba do Norte, medidas do tamanho das conchas dos mariscos foram correlacionadas e verificou-se que à medida que se afastava do Porto Oficina, as medidas morfométricas tendiam a ser mais similares, com forte correlação, em contraste com a área da croa Cidade, a mais próxima do Porto Oficina, que situa-se na desembocadura do Rio Sanhauá. À medida que as demais croas se distanciam, a morfometria tende de ser mais linear. Barreira \& Araújo (2005), em 
estudos com A. flexuosa (= A. brasiliana), relatam que a maturação sexual ocorre em indivíduos com tamanho das conchas entre 12,9 e 17,9 mm. Arruda-Soares, Schaeffer-Novelli \& Mandelli (1982) recomendam a captura do marisco-pedra com conchas apresentando comprimento acima de $20 \mathrm{~mm}$, pois acima deste tamanho os indivíduos têm alcançado um grau de desenvolvimento gonadal, o que possibilita sua reprodução. Na praia de Mangue Seco, litoral norte de Pernambuco, Oliveira (2011) encontrou conchas com comprimento variando de 21 a $25 \mathrm{~mm}$ na estação chuvosa, enquanto Lavander et al. (2011), na mesma praia, registraram comprimento médio de 25,6 $\pm 1,14 \mathrm{~mm}$. Barbosa-Neto et al. (2017) encontraram dois grupos de mariscos-pedra com média de comprimentos de 29,9 e $25,5 \mathrm{~mm}$ na praia de Acaú, litoral da Paraíba. Cidreira-Neto et al. (2018), estudando duas unidades de conservação, no extremo norte e sul da Paraíba, encontraram conchas com comprimentos de 15,0 a 35,0 mm, para a Reserva Extrativista Marinha Acaú-Goiânia (Acaú), e de 15,0 a 28,0 mm para a APA Barra de Mamanguape (Rio Tinto). Em nosso estudo, foram verificados comprimentos de $13,70 \pm 0,92 \mathrm{~mm}$ a $21,76 \pm 0,52 \mathrm{~mm}$. Os comprimentos médios recomendados para a captura foram encontrados na Croa do Marisco $(20,27 \pm 1,81 \mathrm{~mm})$ e no Lombo da Vara $(21,76 \pm$ $0,52 \mathrm{~mm}$ ), que possuem indivíduos com tamanho considerados aptos a conseguir atingir a maturação sexual. Silva et al. (2017), a partir de análises histomorfológicas de A. flexuosa para as croas Cidade e Portinho, verificaram que os indivíduos maiores (adultos) de machos e fêmeas possuem amadurecimento gonadal a partir de 13 $\mathrm{mm}$, corroborando os dados de Barreira \& Araújo (2005). Elas sugerem que o amadurecimento gonadal deve estar ocorrendo mais rápido, devido a necessidade de crescer e se reproduzir em ambientes adversos.

Para a croa Cidade, mesmo que o organismo tenha tido, ao menos, um período reprodutivo, é necessário que a população se reestabeleça, devido a mesma apresentar-se com indivíduos de tamanhos inferior ao préestabelecido como adequado à captura.

A maior riqueza de bactérias endógenas na croa Lombo da Vara pode estar relacionada com a sua maior distância dos centros urbanos e maior saúde ambiental. Este fato proporciona a ocorrência, tanto de espécies tolerantes às interferências antrópicas, quanto de espécies sensíveis. Porém, nem todas as bactérias são patógenas a esses organismos, como geralmente é relatado. Dustel \& Felbeck (1987), em estudos com bivalves da família Lucinidae, mostraram que os indivíduos, por possuírem brânquias grandes, acabam servindo de abrigo para bactérias endossimbiontes, as quais fixam dióxido de carbono sintetizando carboidratos, utilizando a energia liberada pela oxidação dos sulfetos da água do mar. Hentschel \& Felbeck (1995), em estudo com Lucinoma aequizonata, da mesma família, demonstraram que ela possui bactérias endossimbiontes no tecido branquial e consegue respirar em condições com baixos teores de oxigênio e altos de nitrato.

Os morfotipos de bactérias B1, B2, B5 e B8 ocorreram em todos os pontos de coleta (C, P, $\mathrm{M}$ e LV), possivelmente sendo o componente da microbiota natural dos mariscos-pedra (Tabela 2). Os morfotipos B3 e B7, exclusivos da Lomba da Vara e B7, exclusivo da croa do Marisco, podem ser possíveis indicadores de boa qualidade ambiental, pois essas croas são apontadas pelas marisqueiras como mais conservadas e com o tamanho de mariscos mais graúdos, diferentemente das croas Cidade e Portinho, que possuem um alto grau de interferência antrópica, decorrente da lixiviação e deposição de resíduos sólidos residenciais e industriais, trazidos pelos rios Sanhauá e Paraíba do Norte. Considerando os morfotipos de bactérias, acredita-se que o B12 pode ser utilizado como biomonitor do ecossistema, auxiliando no monitoramento da qualidade do estuário do rio Paraíba do Norte.

Curiosamente, a croa Marisco apresenta seis morfotipos de fungos exclusivos (F12 à F17), provocando questionamentos, sendo necessários estudos complementares, que corroborem dados, explicando a maior ocorrência desta microbiota. Silveira, Lobato \& Abreu (2013) relataram que são poucos os estudos de ocorrência de fungos e leveduras em ambientes estuarinos no Brasil. Em seu estudo, foram isoladas leveduras $\mathrm{e}$ encontrados os seguintes gêneros de fungos filamentosos: Alternaria, Aspergillus, Aureobasidium, Bispora, Botryoderma, Botryotrichum, Cladosporium, Chrysosporum, Helminthosporium, Monosporium, Papilospora, Penicillium, Trichoderma, Trichophyton, Actinomycetes e não esporulados, dentre eles, Penicillium e Aspergillus foram os mais frequentes.

A ocorrência de fungos endobióticos na água do estuário pode indicar que esses indivíduos podem estar sendo consumidos pelos mariscos, visto que são filtradores, alimentando-se de micro-organismos e matéria orgânica dissolvida da água. $\mathrm{Na}$ Água do Estuário não existem morfotipos ocorrentes em todas as croas, o F11 é exclusivo da Água do Estuário, na croa Lombo da Vara, sendo, possivelmente, uma espécie sensível 
às variações ambientais. Os fungos exclusivos da croa Cidade são, possivelmente, espécies com ocorrência em ambientes perturbados.

Segundo Silveira, Lobato \& Abreu (2013), os fungos aquáticos podem remover ou degradar poluentes inorgânicos e recalcitrantes funcionando como purificadores da água e são importantes para melhorar a qualidade nutricional do substrato orgânico consumido por organismos detritívoros. Carneiro et al. (2015) apontam duas espécies de leveduras, Kluyveromyces aestuarii (Fell) Van der Walt e Issatchenkia orientalis Kudryavtsev (Candida krusei) como potenciais bioindicadoras. A primeira é encontrada comumente em áreas de domínio do ecossistema manguezal com vegetação bem conservada e a segunda é ligada à poluição orgânica e fecal. Silva \& Gusmão (2015), testando a atividade antifúngica das plantas de mangue (Avicennia schaueriana, Laguncularia racemosa e Rhizophora mangle L.) contra leveduras e dermatófitos, mostraram que os extratos vegetais exibiram uma atividade fraca contra leveduras e, em contrapartida, os dermatófitos se mostraram sensíveis a esses extratos, devido à quantidade de taninos presente. A poluição hídrica pode estar afetando a atividade biológica dos mariscos de forma intensiva, estando as áreas de atividade mais próximas da zona urbana mais afetadas, influenciando o tamanho médio das populações do marisco e a microbiota endógena presente nos indivíduos.

\section{Conclusão}

À medida que as populações de mariscopedra se distanciam da influência do rio Rio Sanhauá, aumenta o tamanho médio dos bivalves. A população de A. flexuosa da croa Cidade pode estar alocando energia para o combate de patógenos e sobrevivência sob condições desfavoráveis, direcionando menor energia para o crescimento e reprodução de seus indivíduos. As croas mais distantes do centro urbano são mais conservadas e possuem uma maior riqueza de bactérias endógenas no marisco, enquanto os fungos não apresentaram diferença significativa entre as croas. Medidas mitigatórias são necessárias para o melhor rendimento da atividade de catação de marisco, tendo como pressuposto a minimização da poluição hídrica, advinda dos centros urbanos e do manejo adequado da mariscagem.

\section{Agradecimentos}

Agradecemos à comunidade Porto Oficina de Bayeux, na pessoa de Neide, ao Centro Formador de Recursos Humanos da Paraíba
(CEFOR), na pessoa do Dr. Eriberto Assis, pelo contato com as marisqueiras. Ao Laboratório ARRE Água e à Prof ${ }^{a} \operatorname{Dr}^{a}$ Norma Buarque Gusmão, pela orientação e análises laboratoriais.

\section{Referências}

ARRUDA-SOARES, H.; SCHAEFFERNOVELLI, Y.; MANDELLI, JR. 1982. "Berbigão" Anomalocardia brasiliana (Gmelin, 1791), bivalve comestível da região da Ilha do Cardoso, Estado de São Paulo, Brasil: aspectos biológicos de interesse para a pesca comercial. Boletim do Instituto de Pesca, v. 9, n. único, p. 21-38.

BARACHO, R. L. 2016. Mariscagem, conhecimento ecológico local e cogestão: $\mathrm{O}$ caso da Reserva Extrativista Acaú-Goiana. Dissertação de Mestrado, Universidade Federal da Paraíba. João Pessoa, PB. Brasil. 138p.

BARBOSA-NETO, M. V.; ALMEIDA, V. S.; RODRIGUES, G. G.; LEITE, S. P. 2017. Análise morfométrica e biométrica de Anomalocardia brasiliana (Bivalvia, Veneridae) na Reserva Extrativista Marinha Acaú-Goiana. Anais III Simpósio de Zoologia da UFPB. João Pessoa-PB. p. 46.

BARREIRA, C. A. R.; ARAÚJO, M. L. R. 2005. Ciclo reprodutivo de Anomalocardia brasiliana (Gmelin, 1791) (Mollusca, Bivalvia, Veneridae) na praia do canto da barra, fortim, Ceará, Brasil. Boletim do Instituto de Pesca, v. 31, n. 1, p. 9-20.

CARNEIRO, M. T.; SILVA, D. M.; CHAGAS, T. G. P.; ZAHNER, V.; ASENSI, M. D.; HAGLER, A. N. 2015. Bioindicadores complementares à colimetria na análise da qualidade da água: $\mathrm{O}$ potencial das Leveduras no lago Juturnaíba/RJ. Sistemas \& Gestão, v. 10, n. 3, p. 542-552.

CAVALCANTI, L. B. 2003 Variações das condições hidrológicas e da clorofila a associadas ao cultivo do camarão marinho Litopenaeus vannamei (Boone, 1931), na região estuarina do rio Paraíba do Norte (Paraíba Brasil). Tese de Doutorado, Universidade Federal de Pernambuco, Recife, Pernambuco, Brasil, 151p.

CIDREIRA-NETO, I. R. G.; NASCIMENTO, D. M.; MORAES, P. X.; RODRIGUES, G. G. 2018. Análise biométrica de Anomalocardia flexuosa em Área de Proteção Ambiental. Journal of Environmental Analysis and Progress, v. 3, n. 2, p. 191-199. 
DUSTEL, D. L., FELBECK, H. 1987. Endosymbiosis in the lucinid clams Lucinoma aequizonata, Lucinoma annulata and Lucinoma floridana: A reexamination of the functional motphology of the gills as bacteria bearing organs. Marine Bio., v. 96, n. 1, p. 79-86.

GUEDES, L. S. 2002. Monitoramento Geoambiental do Estuário do Rio Grande do Norte - por meio da cartografia temática e de produtos com sensoriamento remoto. Dissertação de Mestrado, Universidade Federal do Rio Grande do Norte. Natal, Rio Grande do Norte. Brasil. 90p.

HENTSCHELL, U.; FELBECK, H. 1995. Nitrate Respiration in Chemoautotrophic Symbionts of the Bivalve Lucinoma aequizonata is not Regulated by Oxygen. Applied and Environmental Microbiology, v. 61, n. 4, p. 16301633.

INSTITUTO BRASILEIRO DE GEOGRAFIA E ESTATÍSTICA. Censo 2010. Disponível em: https://ww2.ibge.gov.br/home/estatistica/populaca o/censo2010/default.shtm. Acesso em: dezembro de 2017.

LAVANDER, H. D.; JÚNIOR, L. O. C.; OLIVEIRA, R. L.; NETO, S. R. S.; GALVEZ, A. O.; PEIXOTO, S. R. M. 2011. Biologia reprodutiva da Anomalocardia brasiliana (Gmelin, 1791) no litoral norte de Pernambuco, Brasil. Revista Brasileira de Ciências Agrárias, v. 6, n. 2, p. 344-350.

LUZ, JR.; BOEHS, G. 2011. Reproductive cycle of Anomalocardia brasiliana (Mollusca: Bivalvia: Veneridae) in the estuary of the Cachoeira River, Ilhéus, Bahia. Braz. J. Biol., v. 71, n. 3, p. 679686.

NISHIDA, A. K.; NORDI, N.; ALVES, R. R. M. 2004. Abordagem etnoecológica da coleta de moluscos no litoral paraibano. Tropical Oceanography, v. 32, n. 1, p. 53-68.

OLIVEIRA, I. et al. 2011. Spatial and temporal distribution of the shellfish Anomalocardia brasiliana (Gmelin, 1791) on Mangue Seco beach, Pernambuco, Brazil. Int. J. Aqu. Sci., v. 2, n. 1, p. 68-79.

PINTO, S. L. 2012. Os moluscos Anomalocardia brasiliana (Gmelin, 1791) e Tagelus plebeius (Lightfoot, 1786) como bioindicadores de poluição orgânica no estuário da bacia do Pina, Recife-PE, Brasil. Tese de Doutorado, Universidade Federal de Pernambuco. Recife, Pernambuco, Brasil, 114p.

ROCHA, L. M. 2013. Ecologia Humana e Manejo participativo da pesca do Búzio Anomalocardia brasiliana (Gmelin, 1791) (Bivalvia: Veneridae) na Reserva de Desenvolvimento Sustentável Estadual Ponta do Tubarão (RN). Tese de Doutorado, Universidade Federal do Rio Grande do Norte, Natal, Rio Grande do Norte, Brasil, 139 p.

RODRIGUES, A. M. L.; BORGES-AZEVEDO, C. M.; HENRY-SILVA, G. G. 2010. Aspectos da biologia e ecologia do molusco bivalve Anomalocardia brasiliana (Gmelin, 1791) (Bivalvia, Veneridae). R. Bras. Bioci., v. 8, n. 4, p. 377-383.

SILVA, M. R. O.; GUSMÃO, N. B. 2015. Antifungal activity of leaf and bark extracts from Brazilian mangrove plants. The Battle Against Microbial Pathogens: Basic Science, Technological Advances and Educational Programs (A. Méndez-Vilas, Ed.).

SILVA, T. M. S.; LIMA, M. I. A.; MARINHO, A. G. C.; RODRIGUES, J. H. 2017. Biomorfometria e Histologia do Marisco Pedra (Anomalocardia flexuosa) do estuário do rio Paraíba do Norte. Anais V Congresso Nacional de Educação Ambiental e Biogeografia. p. 257.

SILVEIRA, E. S.; LOBATO, R. C.; ABREU, P. C. 2013. Fungos e leveduras no estuário da lagoa dos patos e praia do Cassino, RS, Brasil. Atlântica, v. 35, n. 1, p. 45-54. 